\title{
Systematic Review of Natural Resource Management using Multiagent Systems and Role-Playing Games
}

\author{
Giovani Farias ${ }^{1}$, Bruna Leitzke ${ }^{1}$, Míriam Born ${ }^{2}$, \\ Marilton Aguiar ${ }^{2}$, Diana F. Adamatti ${ }^{1}$ \\ 1 Universidade Federal do Rio Grande (FURG), \\ Programa de Pós-Graduação em Modelagem Computacional (PPGMC), \\ Rio Grande, RS, Brazil \\ 2 Universidade Federal de Pelotas (UFPel), \\ Programa de Pós-Graduação em Computação (PPGC), \\ Pelotas, RS, Brazil \\ \{marilton,mbborn\}@inf .ufpel.edu.br
}

\begin{abstract}
A good way of clarifying controversies is to the best quality studies in the area in question. In this way, the systematic literature review is a type of research focused on a well-defined subject, which aims to identify, select, evaluate and synthesize evidence of a specific research topic. The systematic literature review purpose is to build an overview of a specific issue and provide a summary of the literature, guaranteeing standardization and precision. Natural resource management is an area that seeks better ways to manage land, water, plants, and animals, based on the life quality of people now and for future generations. This area gained visibility with the notion of sustainability. Natural resource management focuses specifically on the scientific-technical understanding of resources and ecology and how these resources can support animal life. An approach that can help in the decision-making of this complex area is the integration of multiagent systems and role-playing games. This paper presents a systematic literature review of these three areas: natural resource management, multiagent systems, and role-playing games.
\end{abstract}

Keywords: natural resource management, multiagent systems, role-playing games.

\section{Introduction}

Natural resource management aims to think of efficient ways to organize and plan the ecosystem. In addition, it is important using these resources economically and sustainably, thinking about the demand of the population. Such, the management can be carried out in a coherent way and without harming the parties involved, i.e., it is necessary to understand the problems related to the ecosystem and its dynamics, and to deal with the social process involved in this system 
[17]. Some models, such as biophysical ones, are often not enough to describe and analyze these processes since they are not based on the decision-making of the organizations and groups involved in the problem. Complex models are determined from the variety of non-linear behaviors within these systems [15]. In this way, it is possible to develop models that describe the dynamics between the parties involved and the management of resources.

Some techniques developed from the advances in the field of Artificial Intelligence (AI) can be used to execute simulations of social phenomena based on their virtual representations [4]. MultiAgent Systems (MAS) and Role-Playing Games (RPG) are some of these techniques, and they have been used to model and simulate the dynamics of complex systems [7].

Multiagent systems can be defined in terms of agents that interact with each other or with the environment. From this, it is possible to observe the decisionmaking of each agent individually and all of them, collectively. Besides that, the impact of each action on the environment could be analyzed. This concept can be understood as a "bottom-up" model since the development basing in a micro-scale shows results in macro-scale, generating consequences throughout the system. Based on this, a MAS can be designed to simulate the different strategies of resource management and verify their impact on the environment [13]. On the other hand, RPG can be used in different integrated ways to MAS, such as paper or computational models. They can assist in data collection, model validation, or the construction of tools that assist the parties involved during the participatory decision-making process [5].

There are several types of integration between MAS and RPG. These techniques can be used in parallel, i.e., exchanging information throughout the process of model development, or they can be developed in a sequential way, from the same conceptual model. In this integration, players themselves can analyze their decisions and can improve their strategies in each proposed scenario and, consequently, generate different responses to the system $[12,9]$.

Systematic Literature Review (SLR) consists of a specific scientific methodology that goes one step further than the simple overview. A systematic review is a method that allows specialists to obtain relevant and quantified results [18]. The main idea is to identify, select and produce evidence regarding research in a particular topic. It aims to integrate empirical research in order to create generalizations. Each SLR involves specific objectives, which allows the researchers to critically analyze the collected data, to resolve conflicts detected in the literature material and to identify issues for planning a future investigation.

In this paper, we have as main goal to present an SLR about three areas: Natural Resource Management, Multiagent Systems, and Role-Playing Games, because the Natural Resource Management is a very complex area and some studies involving the MAS and RPG areas are being done, but with different approaches, to solve different problems.

In this way, the paper is structured as following: in Section 2 are presented the main concepts in the two computational areas, MAS and RPG, and how to integrate them. Section 3 presents all methodology applied to SLR in this paper, 
like databases and keywords. Section 4 shows the papers resulting from the SLR and the approach of each one. Finally, in Section 5 the conclusions and future works of the paper are presented.

\section{Theoretical Background}

\subsection{Multiagent Systems - MAS}

Artificial Intelligence emerged in the 1950s on the supported of several areas such as philosophy, mathematics, psychology, neuroscience, economics, linguistics, and computer engineering [27]. In the context of AI, the concept of intelligent agents emerges in 1995, the internet being the ideal environment for the use of these agents in the development of information search mechanisms, recommendation systems, product launches of a company, monitoring of market trends, etc.

According to [27]: "an agent is something able to perceive its environment through sensors and act on this environment through actuators", considering the agent's ability to execute of specific tasks/actions and to reason about a particular domain. MAS is composed of several agents interacting in an environment. Each agent of a system has individual behavior, but they must be able to interact with others in an organized way, in this way characteristics such as cooperation, coordination, competition, and negotiation are relevant $[3,8]$, since most problems to be solved aim a way distributed of the solution.

In the literature, there are several benefits of using MAS: (i) speed in solving problems, due to the inherent complexity of concurrent processing; (ii) increased flexibility and scalability by connecting multiple systems; (iii) increasing the capacity to respond to a given problem because all resources are located in the same environment, among others. MAS is currently used in the natural resources management domain. With this technique, it is possible to reproduce the knowledge and reasoning of several heterogeneous agents, which together need to solve common planning problems [10]. This SLR presents that MAS is widely used in this domain and, together with RPG, have satisfactory solutions.

\subsection{Role-Playing Games - RPG}

Role-playing game is a technique very used in training since it can put the players in situations of decision-making similar to the real ones but without effective consequences. In particular, large companies have used RPG in training courses, because of the playfulness involved in games, facilitating training and/or learning of specific subject [24]. Role-playing is a type of game where players "play/interpret" a character, created within a certain scenario (also called environment). The characters respect a system of rules, which serves to organize their actions, determining the limits of what can and can not be done [23].

Role-playing game is situated between games and theater and consist of a technique where players' rules and behaviors are determined, as well as an 
imaginary (environment) context [2]. In this way, RPG could reveal some aspects of social relationships, allowing direct observation of interactions between players [6]. In an RPG, there are no winners and losers, given that it has an aspect of collaboration rather than competition. In the end, players must complete a story built from the rules of the game, in the achievement of individual and/or collective goals [2].

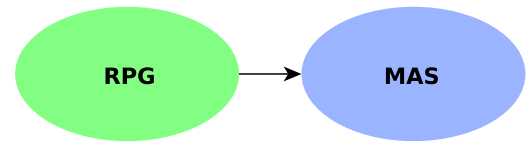

(a)

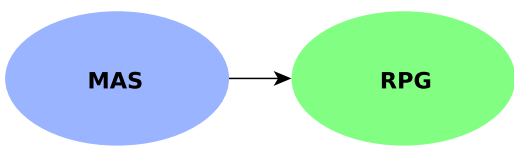

(b)

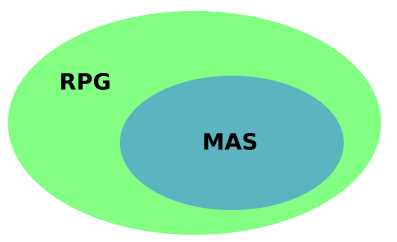

(c)

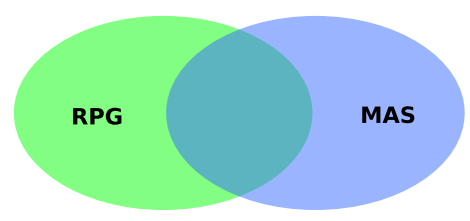

(d)

Fig. 1. Integration between RPG and MAS: (a) RPG $\rightarrow$ MAS; (b) MAS $\rightarrow$ RPG; (c) RPG + MAS; (d) RPG ++ MAS.

\subsection{Integration between RPG and MAS}

There are in the literature some ways to integrate RPG and MAS. Figure 1 presents four ways for this integration ${ }^{3}$ :

(a) (RPG $\rightarrow$ MAS): RPG is playing for the stakeholders (using cards and chips in a table) and, in the final of the game, all cards are collected and information about the game is transformed in a multiagent simulation. In this type of integration, normally, the RPG is used to collect information about the problem and how the stakeholder take their decision-making;

(b) (MAS $\rightarrow$ RPG): the MAS is defined based on the knowledge of the developers. After, an RPG (with the same ideas of the MAS) is paying for the stakeholders, to validate the simulation;

${ }^{3}$ The components in green in (a), (b) and (c) represent activities in "paper", i.e., activities that are not computational. In the component (d) all components are computational. 
(c) (RPG + MAS): an RPG is developed, but it needs computational support to execute because the rules and the calculations of the game are complex. In this way of integration, the RPG and MAS working together. The stakeholders play the game using cards, but all actions in the game process in a multiagent simulation;

(d) $(\mathrm{RPG}++\mathrm{MAS})$ : this way of integration is unique that the two techniques are computational. The RPG is developed as a software and all calculation is done by the multiagent simulation. In this type of integration, if the RPG is developed to execute in the Web, the stakeholders could play in remote places.

In next Sections, when we address each type of integration, we have used the nicknames: $(\mathrm{RPG} \rightarrow \mathrm{MAS}),(\mathrm{MAS} \rightarrow \mathrm{RPG}),(\mathrm{RPG}+\mathrm{MAS})$ and $(\mathrm{RPG}++$ MAS).

\section{Methodology}

In this section, we describe the protocol used to perform the SLR [22] about natural resource management using multiagent systems and role-playing games. Four reviewers conducted and defined the steps of this SLR. In this work, the goal was to search in the literature for works addressing MAS and RPG used to enhance natural resource management. The main question defined for the SLR was: "What are the main works addressing natural resource management using a multiagent systems and role-playing games?" (Table 1).

Table 1. Protocol of the systematic literature review.

\begin{tabular}{c|l}
\hline $\begin{array}{c}\text { Main } \\
\text { question }\end{array}$ & $\begin{array}{l}\text { "What are the main works addressing natural resource management } \\
\text { using multiagent systems and role-playing games?" }\end{array}$ \\
\hline Objective & $\begin{array}{l}\text { The purpose of this SLR was to search in the literature for studies, } \\
\text { especially in the last } 10 \text { years }(2009-2019), \text { addressing natural resource } \\
\text { management using multiagent systems and role-playing games. }\end{array}$ \\
\hline $\begin{array}{c}\text { Inclusion } \\
\text { criteria }\end{array}$ & $\begin{array}{l}\text { Studies that contain the keywords and their constraints (Table 3): } \\
\text { - Multiagent System; } \\
\text { - Role-Playing Game; } \\
\text { - Natural Resource Management. }\end{array}$ \\
\hline $\begin{array}{c}\text { Exclusion } \\
\text { criteria }\end{array}$ & $\begin{array}{l}\text { The study is not in English; } \\
\text { The study is not in the searched databases; } \\
\text { The study has not the searched keywords. }\end{array}$ \\
\hline
\end{tabular}

The keywords used in the query were defined in the reviewers meeting, and they were changed based on the first searches. We used five databases shown in Table 2. The searches were performed in April 2019 and the string to search in all databases was the same presented in Table 3. 
Table 2. Databases used in this work.

\begin{tabular}{c|l}
\hline Name & URL \\
\hline ACM & https://dl.acm.org/ \\
\hline IEEE & https://ieeexplore.ieee.org/Xplore/home.jsp \\
\hline ScienceDirect & https://www.sciencedirect.com/ \\
\hline Scopus (Elsevier) & https://www.scopus.com/ \\
\hline SpringerLink & https://link.springer.com/ \\
\hline
\end{tabular}

Table 3. Keywords used to define the string to SLR.

\begin{tabular}{cccc}
\hline ("multiagent system" & OR & "multiagent systems" & OR \\
"multiagents system" & OR & "multiagents systems" & OR \\
"multi-agent system" & OR & "multi-agent systems" & OR \\
"multi-agents system" & OR & "multi-agents systems") & \\
\hline \multicolumn{5}{c}{ AND } & & \\
\hline ("role-playing game" & OR & "role-playing games" & OR \\
"role playing game" & OR & "role playing games" & OR \\
"role game" & OR & "role games") & \\
\hline ("natural resource management" & OR "natural resources management") \\
\hline
\end{tabular}

A total of 352 works were collected from the databases (0 from ACM, 1 from IEEE, 27 from ScienceDirect, 234 from Scopus (Elsevier) and 90 from SpringerLink). The records were downloaded in bibtex and comma-separated values (csv) formats. The collected references file was edited/organized by software, Mendeley ${ }^{4}$ and JabRef ${ }^{5}$. The JabRef was used to remove redundant references and the Mendeley was used to share the reading list and collaboratively tag and annotate research papers. A total of 281 references were qualified for the data evaluation step.

The data evaluation consists of the phase in which the reviewers analyzed each reference collected and they define the papers that were included in the SLR list. This data evaluation was performed according to the following steps: title and abstract evaluation was the step where each reviewer evaluated if the paper were related to the main question based on its title and abstract. In this step, it was evaluated if the papers complied with the main question, keywords related to the main question and objectives were searched in the title and abstract. This step was important to eliminate papers that had no relationship with the searched theme following the exclusion criteria. In the title and abstract evaluation, the reviewers approved 22 papers.

In the introduction reading evaluation, the reviewers read the introduction of each paper classified for this step. Thus, the reviewers verified which papers described better the main question and attend to the objective of this SLR. Also,

4 (https://www.mendeley.com/)

${ }^{5}$ (http://www.jabref.org/) 
it was possible to verify if the keywords used in the database search were present in these papers. In the introduction reading, the reviewers approved 12 papers.

Finally, in the complete reading evaluation, the final step of data evaluation, the reviewers performed full-text reading and evaluate the studies that better complies with the requirements of the main question of the SLR. In this step, the reviewers approved 10 papers, as presented in Table 4.

\section{Results}

In this section is presented the results obtained in SLR. Table 4 presents the list of authors, as well as how the MAS and RPG was integrated and where they were applied.

Table 4. Result of the systematic review.

\begin{tabular}{|c|c|c|}
\hline Paper & Integration & Application \\
\hline Adamatti et al., 2009 [1] & $\mathrm{RPG}++\mathrm{MAS}$ & quality of water resources \\
\hline Campo et al., 2009 [11] & $\mathrm{RPG}+\mathrm{MAS}$ & community forest management \\
\hline Farolfi et al., $2010[14]$ & $\mathrm{RPG} \rightarrow \mathrm{MAS}$ & management of water resources \\
\hline Ruankaew et al., 2010 [26] & $\mathrm{RPG} \rightarrow \mathrm{MAS}$ & management of forest resources \\
\hline Souchère et al., 2010 [28] & $\mathrm{RPG} \rightarrow \mathrm{MAS}$ & management of erosive runoff \\
\hline Gourmelon et al., 2013 [16] & $\mathrm{RPG}+\mathrm{MAS}$ & land use management \\
\hline Le Page et al., 2014 [19] & $\mathrm{RPG} \rightarrow \mathrm{MAS}$ & land/water and labor migration \\
\hline Rebaudo et al., 2014 [25] & $\mathrm{MAS} \rightarrow \mathrm{RPG}$ & integrated pest management \\
\hline Le Page et al., 2016 [20] & $\mathrm{RPG}++\mathrm{MAS}$ & $\begin{array}{l}\text { conservation and management } \\
\text { of natural resources }\end{array}$ \\
\hline Le Page and Perrotton, 2018 [21] & $\mathrm{RP}$ & $\begin{array}{l}\text { coexistence between human } \\
\text { populations and wildlife }\end{array}$ \\
\hline
\end{tabular}

In the work [1], the authors have used the methodology called GMABS, that was created from the integration of RPG and MAS simulator. Using this methodology, the authors developed two prototypes in the context of periurban catchment basin. The first prototype, called JogoMan, is a role-based game: all players need to be physically present at the same place and time, and there is a minimum number of participants required to play the game. In the second prototype, called ViP-JogoMan, it was possible to insert virtual players who could imitate real behaviors and capture autonomy, social skills, reaction and adaptation of real players. For the modeling of virtual players, the BDI (belief, desire, and intention) architecture was used. In this work, the first version is the $(\mathrm{RPG}+\mathrm{MAS})$ integration and the second version is the $(\mathrm{RPG}++\mathrm{MAS})$ integration. As a conclusion of the paper, the authors present some test results obtained with the two prototypes as well as a preliminary discussion on how the insertion of virtual players affected the results of the game.

The work [11] reports on the experiences and lessons learned from applying a multiagent system model to study the dynamics and complex interactions among 
stakeholders in forest management, managed by three villages on Palawan Island (Philippines). This model was developed using the ComMod (The Companion Modeling) approach, which consists of the application of RPG and computational simulation, in order to develop a collaborative resource management plan. Based on this approach, the authors concluded that the use of RPG and the multiagent simulation allowed researchers to understand how stakeholders act in relation to decision-making about a controlled environment and also how they devise resource management strategies. In this work, the integration was (RPG+MAS).

In the paper [14], the authors present a multiagent model created from the ComMod approach of the Kat River Valley, Eastern Cape, South Africa. This model was called KatAWARE and, in this work, the goal was to propose a detailed methodology to formalize and systematize the modeling phases of this approach. In the context, the case study was the Kat River basin and the specification of the system structure and its dynamics was represented in diagrams based on Unified Modeling Language (UML). In this way, the work presented three iterations/models with the purpose of aggregating the innumerable sources of knowledge and data with the objective of developing a collective management plan. RPG proved to be a facilitating tool in these discussions, implementation and simulations were important to explore scenarios and discuss results. It is a (RPG $\rightarrow$ MAS) integration because the information obtained from the RPG sessions served to support the scenarios of the simulations.

The paper [26] presents theoretical and experimental aspects of the ComMod approach, using as experiment the conflict between two ethnic communities into a national park in northern Thailand. In the RPG sessions, fundamental issues such as deforestation, biodiversity conservation, and community livelihoods were discussed, and from this discussion, the information was represented in a multiagent simulator. The integration in this work is (RPG $\rightarrow$ MAS) since the data collected in the RPG workshops supported the multiagent system. The conclusion of this research showed that collaborative interactions between researchers and stakeholders increased communication and collective learning, improving the integrated management of sustainable development of renewable resources.

In the [28], the authors propose the creation of a RPG, based on the ComMod approach, in order to facilitate negotiation on erosive runoff management. The game was organized in two sessions with two different river basin management committees in the Pays de Caux (France), in order to discuss and share knowledge about the environment and the stakeholders. This works also is a (RPG $\rightarrow$ MAS) integration because the information obtained from the RPG sessions provided support of the simulations. In the results reported by the authors, despite the inherent complexity of the management problem, the group of players managed to reduce flow by $20 \%$ to $50 \%$ through a dialogue on grassland, storage tanks, and management of the off-season.

The work of [16] presents the changes in land use in the island of Ushan, which is part of the Armorique Regional Nature Park in Brittany - France, has suffered 
from landslides, resulting in consequences in the landscape, traditional activities and biodiversity. From the ComMod approach, researchers, together with the biosphere reserve manager and the Center d'Etude du Milieu d'Ouessant, conducted a study on the interactions between social and environmental dynamics on this protected island. The objectives of the work were: the conception of a model, the implementation of a geographic MAS and the design of a RPG game, to assist in the decision making of the interested parties and in the sustainable management of land use.

The MAS was developed based on the ARDI method and was designed and implemented on the CORMAS platform, where it was refined and validated at each stage of the discussion. The integration used among the techniques was (MAS + RPG) because, at the end of each turn of the sessions of RPG, the MAS provided the changes of land induced by the actions of the players. RPG sessions were held with individuals involved in the project where they had a critical eye and compared the results of the game to reality.

The work [19] models a MAS with a group of rain-fed rice farmers in Thailand, to investigate interactions between the availability of water and the migration of labor in rice production. Firstly, the stakeholders played a RPG to discovery the dynamic of the envirnoment and improve new game sessions and after, to develop the MAS. This work is a (RPG $\rightarrow$ MAS) integration. As results, the authors concluded that this model is a communication tool used by local scientists and farmers, and it has been developed to exchange and integrate knowledge on land-use-water interactions and labor migration. The model has three social levels: individual, family and village.

In the work [25], the authors analyze the dissemination of information on Integrated Pest Management (IPM) in communities of small Andean farmers, Peru. The researchers designed a MAS of the Andean agricultural system and from that, developed the RPG as a paper model, in this case, the integration used between the techniques was (MAS $\rightarrow$ RPG). They tested the game with 90 potato farmers from 6 communities in three countries. After RPG sessions, they conducted interviews with farmers and concluded that the RPG based on MAS is a tool that can be used for the teaching and dissemination of IPM information, which may reduce vulnerability to pest risks in the region.

The work [20] presents the ReHab game. It is an RPG-based game used to introduce the main ideas of natural management to students in the first years of a graduate course in the area. The main goal of the game is to find the equilibrium of the environment. The game has two phases: the first one, where the players can not communicate with the colleagues and they must choose their actions individually; the second one, where they communicate with the colleagues and take their decisions about the game actions. It is an (RPG ++ MAS) integration because all system is computational and each player plays in a computer. However, each simulation allows to one player (the game is not a collective simulation). The authors concluded that a well-designed RPG allows players (individually and collectively) to shape, learn about, and reflect upon responses from the socio-ecological system to various management regimes. 
The idea of the work in [21] is to propose a new approach to model participatory multiagent simulation, called KILT. This approach differs to KISS and KIDS approaches, well-known in literature because the simulations could be stylized to socio-ecosystems and stimulate the social learning of the stakeholders. It is an $(\mathrm{RPG}+\mathrm{MAS})$ integration because the stakeholders play in cards and the actions are computed in a multiagent simulation. The authors conclude that with this approach, the focus of interaction can be set on computer-participant interactions (participants observe the simulation run in the manner of a cinema audience), or on participant-participant interactions (participants can intervene while the simulation runs or at intervals provided during the run).

\section{Conclusions}

This work proposed a SLR about three areas, Natural Resource Management, MAS and RPG, in order to identify relevant research developed in last years. The main objective of this type of review is to obtain consistent subsidies, in relation to a specific research, bringing relevant works with significant scientific contributions.

In addition to the identification of research in these areas, we have defined the ways of integration between RPG and MAS. This definition is essential for the understanding of related works and possible researches involved in this context. The works mentioned here present four ways of integration between RPG and MAS, and mostly, were developed from the ComMod approach, created by the CIRAD group, France.

Other important finding of this SLR is that until 2010 were published several researches and, in the last years, this number was reduced. However, the results of all works used in this SLR were very satisfactory, which proves that this area has huge potential to bring contributions.

Acknowledgments. This study was financed in part by the Coordenação de Aperfeiçoameto de Pessoal de Nível Superior (CAPES/Brasil) and Agência Nacional de Águas (ANA/Brasil) - Edital N 16/2017.

\section{References}

1. Adamatti, D.F., Sichman, J.S., Coelho, H.: An analysis of the insertion of virtual players in GMABS methodology using the ViP-JogoMan prototype. Journal of Artificial Societies and Social Simulation 12(3) (2009)

2. Adamatti, D.F., Sichman, J.S., Coelho, H.: Utilização de RPG e MABS no desenvolvimento de sistemas de apoio a decisão em grupos. Anais do IV Simpósio Brasileiro de Sistemas Colaborativos SBSC 2007 p. 15 (2007)

3. Alvares, L.O., Sichman, J.S.: Introdução aos sistemas multiagentes. In: XVII Congresso da SBC-Anais JAI'97 (1997) 
4. Barnaud, C., Bousquet, F., Trebuil, G.: Multi-agent simulations to explore rules for rural credit in a highland farming community of northern thailand. Ecological Economics 66(4), 615-627 (jul 2008), https://linkinghub.elsevier.com/retrieve/pii/S0921800907005228

5. Barreteau, O., Abrami, G.: Variable time scales, agent-based models, and role-playing games: The PIEPLUE river basin management game. Simulation \& Gaming 38(3), 364-381 (sep 2007), http://journals.sagepub.com/doi/10.1177/1046878107300668

6. Barreteau, O., Le Page, C., D'aquino, P.: Role-playing games, models and negotiation processes. Journal of Artificial Societies and Social Simulation 6(2) (2003)

7. Boissau, S., Castella, J.C.: Constructing a Common Representation of Local Institutions and Land Use Systems through Simulation-Gaming and Multiagent Modeling in Rural Areas of Northern Vietnam: The SAMBAWeek Methodology. Simulation \& Gaming 34(3), 342-357 (sep 2003), http://journals.sagepub.com/doi/10.1177/1046878103255789

8. Bordini, R.H., Vieira, R., Moreira, Á.F.: Fundamentos de sistemas multiagentes. XX Jornada de atualização em informática (JAI) 2 (2001)

9. Bousquet, F., Castella, J.C., Trébuil, G., Barnaud, C., Boissau, S., Kam, S.P.: Using Multi-Agent Systems in a Companion Modelling Approach for Agroecosystem Management in South-East Asia. Outlook on Agriculture 36(1), 57-62 (mar 2007), http://journals.sagepub.com/doi/10.5367/000000007780223650

10. Bousquet, F., Le Page, C.: Multi-agent simulations and ecosystem management: a review. Ecological modelling 176(3-4), 313-332 (2004)

11. Campo, P.C., Mendoza, G.A., Guizol, P., Villanueva, T.R., Bousquet, F.: Exploring management strategies for community-based forests using multi-agent systems: A case study in Palawan, Philippines. Journal of Environmental Management 90(11), 3607-3615 (aug 2009), https://linkinghub.elsevier.com/retrieve/pii/S0301479709002321

12. Dray, A., Perez, P., LePage, C., D'Aquino, P., White, I.: Companion modelling approach: The AtollGame experience in Tarawa atoll (Republic of Kiribati). In: MODSIM05 - International Congress on Modelling and Simulation: Advances and Applications for Management and Decision Making, Proceedings. pp. 1601-1609. Melbourne, VIC (2005)

13. Etienne, M.: SYLVOPAST: A multiple target role-playing game to assess negotiation processes in sylvopastoral management planning. Journal of Artificial Societies and Social Simulation 6(2), 1-26 (2003)

14. Farolfi, S., Müller, J.P., Bonté, B.: An iterative construction of multi-agent models to represent water supply and demand dynamics at the catchment level. Environmental Modelling \& Software 25(10), 1130-1148 (oct 2010), https://linkinghub.elsevier.com/retrieve/pii/S1364815210000770

15. García-Barrios, L., Speelman, E., Pimm, M.: An educational simulation tool for negotiating sustainable natural resource management strategies among stakeholders with conflicting interests. Ecological Modelling 210(1-2), 115-126 (jan 2008), https://linkinghub.elsevier.com/retrieve/pii/S0304380007003663

16. Gourmelon, F., Chlous-Ducharme, F., Kerbiriou, C., Rouan, M., Bioret, F.: Role-playing game developed from a modelling process: A relevant participatory tool for sustainable development? A co-construction experiment in an insular biosphere reserve. Land Use Policy 32, 96-107 (may 2013), https://linkinghub.elsevier.com/retrieve/pii/S0264837712002037 
17. Gurung, T.R., Bousquet, F., Trébuil, G.: Companion Modeling, Conflict Resolution, and Institution Building: Sharing Irrigation Water in the Lingmuteychu Watershed, Bhutan. Ecology and Society 11(2) (2006)

18. Kitchenham, B.: Procedures for performing systematic reviews. Tech. rep., Joint Technical Report Software Engineering GroupKeele University, United Kingdom and Empirical Software Engineering, National ICT Australia Ltd, Australia (2004)

19. Le Page, C., Naivinit, W., Trébuil, G., Gajaseni, N.: Companion modelling with rice farmers to characterise and parameterise an agent-based model on the land/water use and labour migration in northeast Thailand. In: Empirical Agent-Based Modelling - Challenges and Solutions, pp. 207-221. Springer, New York, NY (2014), http://link.springer.com/10.1007/978-1-4614-6134-0

20. Le Page, C., Dray, A., Perez, P., Garcia, C.: Exploring how knowledge and communication influence natural resources management with ReHab. Simulation \& Gaming 47(2), 257-284 (apr 2016), http://journals.sagepub.com/doi/10.1177/1046878116632900

21. Le Page, C., Perrotton, A.: KILT: A modelling approach based on participatory agent-based simulation of stylized socio-ecosystems to stimulate social learning with local stakeholders. In: Dimuro G.P., A.L. (ed.) Lecture Notes in Computer Science (including subseries Lecture Notes in Artificial Intelligence and Lecture Notes in Bioinformatics), vol. 10798 LNAI, pp. 156-169. Springer Verlag (2018), http://link.springer.com/10.1007/978-3-319-91587-6_11

22. Mariano, D.C.B., Leite, C., Santos, L.H.S., Rocha, R.E.O., de Melo-Minardi, R.C.: A guide to performing systematic literature reviews in bioinformatics. arXiv e-prints arXiv:1707.05813 (Jul 2017), https://ui.adsabs.harvard.edu/abs/2017arXiv170705813M

23. Pereira, C.E.K.: Construção de personagem \& aquisição de linguagem: O desafio do rpg no ines. In: vol. 10,(jul/dez) Rio de Janeiro INES, 2004 Semestral ISSN 1518-2509 1-Forum-Instituto Nacional de Educação de Surdos. p. 7 (2003)

24. Perrotton, A., Garine-Wichatitsky, D., Valls Fox, H., Le Page, C., et al.: My cattle and your park: codesigning a role-playing game with rural communities to promote multistakeholder dialogue at the edge of protected areas. Ecology and Society 22(1) (2017)

25. Rebaudo, F., Carpio, C., Crespo-Pérez, V., Herrera, M., de Scurrah, M.M., Canto, R.C., Montañez, A.G., Bonifacio, A., Mamani, M., Saravia, R., Dangles, O.: Agentbased models and integrated pest management diffusion in small scale farmer communities. In: Integrated Pest Management, pp. 367-383. Springer Netherlands, Dordrecht (2014), http://link.springer.com/10.1007/978-94-007-7802-3_15

26. Ruankaew, N., Le Page, C., Dumrongrojwattana, P., Barnaud, C., Gajaseni, N., van Paassen, A., Trébuil, G.: Companion modelling for integrated renewable resource management: a new collaborative approach to create common values for sustainable development. International Journal of Sustainable Development \& World Ecology 17(1), 15-23 (feb 2010), https://www.tandfonline.com/doi/full/10.1080/13504500903481474

27. Russell, S., Norvig, P.: Artificial Intelligence: A Modern Approach. Prentice Hall (2003)

28. Souchère, V., Millair, L., Echeverria, J., Bousquet, F., Le Page, C., Etienne, M.: Co-constructing with stakeholders a role-playing game to initiate collective management of erosive runoff risks at the watershed scale. Environmental Modelling \& Software 25(11), 1359-1370 (nov 2010), https://linkinghub.elsevier.com/retrieve/pii/S1364815209000656 